\title{
A IMAGEM DO IMIGRANTE: REINVENÇÃO, PASSADO E VOZ ${ }^{1}$
}

Dionei Mathias (UFSM)

Resumo: O romance $A$ casa do espelhos foi publicado originalmente em francês, em 1994, pelo escritor canadense de origem brasileira Sergio Kokis. O romance pode ser lido como parte de um conjunto de obras produzidas na literatura contemporânea sobre a experiência do imigrante. Com foco nesse aspecto do enredo, este artigo pretende discutir a imagem do imigrante no início de sua inserção no país de acolhimento, as estratégias que ele adota para administrar suas memórias e seu passado e, por fim, na forma como reflete sobre a obtenção de uma voz própria. A imagem do imigrante que surge nesse contexto se difere de muitas outras obras desse campo literário, ao optar por traçar uma imagem menos voltada para o confronto das culturas e mais concentrada nas estratégias subjetivas de administração do corpo, dos afetos, das memórias e da própria voz. A base teórica dessa discussão se vale do conceito de identidade, entendido aqui como narrativa produzida a partir de diversas negociações entre sujeito, cultura e memória pessoal, criando assim uma voz própria.

Palavras-chave: Sergio Kokis; A casa dos espelhos; Imigrante.

Abstract: The novel $A$ casa dos espelhos was originally published in French, in 1994, by Sergio Kokis, a Canadian writer of Brazilian origin. This novel can be read as part of a group of novels written in contemporary literature that deal with the immigrant experience. Focussing on this aspect of the plot, this articles aims to discuss the immigrant image as he arrives and fits in the new country, the strategies he adopts to deal with his memories and his past and, at last, the way he thinks about obtaining his own voice. The immigrant image conjured in this context differs from many other novels discussed in this literary field, by opting to create an image less focussed on the clash of cultures and more interested in the subjective strategies of body, feeling, memory and voice management. The theoretic basis of this discussion draws on the concept of identity, understood here as a narrative produced out of negotiations between subject, culture and personal memory, engendering a voice of its own. Keywords: Sergio Kokis; A casa dos espelhos; Immigrant.

1 Título em inglês: "The Immigrant Image: reinvention, past and voice". 


\section{INTRODUÇÃO}

O pertencimento a uma determinada geração representa um elemento central na literatura oriunda de fluxos migratórios. Imigrantes da primeira geração, isto é, aqueles que deixaram um espaço sociocultural para migrar para outro, apresentam uma constelação de inquietudes completamente diferente daquela experimentada pela segunda ou terceira geração, ou seja, os filhos daqueles que imigraram. Isso vale tanto para o plano extraficcional no qual se encontra o escritor e o modo como este se insere nas práticas da escrita da respectiva literatura nacional, como também para o plano ficcional da realidade diegética e das formas de estetização da experiência migrante. O que basicamente diferencia essas experiências é o relacionamento com o passado e suas memórias, o modo como esses diferentes indivíduos administram seu posicionamento na sociedade em que circulam prioritariamente, por fim, também o relacionamento com a língua e a cultura locais. Com efeito, representantes de gerações diversas enfrentam desafios relacionados a legitimação e pertencimento que partem de premissas diferentes, demandando do sujeito a mobilização de estratégias específicas para obtenção de uma configuração existencial em consonância com suas necessidades. 
No centro dessa discussão, encontra-se o conceito da identidade. Este pode ser entendido como narrativa pessoal, na qual o sujeito relaciona informações pessoais negociadas em processos de interação, com o objetivo de alcançar uma concatenação narrativa que o represente no palco social (KEUPP, 2002). Nesse trabalho de negociação narrativa, o sujeito precisa processar os sentidos que circulam numa determinada sociedade, portanto, administrar a carga cultural que cada espaço utiliza para guiar suas ações. Ao mesmo tempo, essa negociação também interage com o próprio corpo, o modo como este internaliza as imposições sociais e processa as memórias decorrentes da interação com outros atores sociais. Nesse embate entre sujeito, cultura e memória pessoal, surge uma voz própria que busca articular o posicionamento do sujeito na cartografia de fala e da autopercepção.

No romance $A$ casa dos espelhos de Sergio Kokis, o narrador autodiegético relata suas experiências com a imigração, concatenando o presente diegético da imigração com a reconstrução das memórias de infância no Brasil, seu país de origem. Ao contrário de muitos outros personagens ficcionais que pertencem ao universo literário dos fluxos migratórios, o protagonista traz consigo, quando opta por imigrar ao Canadá, um capital intelectual e simbólico 
em forma de formação institucional recebida na França que facilita sua inserção no novo contexto cultural. Bourdieu (1983, p.183) fala de capital econômico, social e cultural que podem ser transformados respectivamente em outros capitais, definindo, de certo modo, as coordenadas nas quais o ator social pode circular e as interações das quais pode participar. O protagonista detém uma base sólida nesse quesito. Isso ocorre não somente por ter um domínio seguro da língua francesa, mas também por ter uma habilidade de reflexão e distanciamento que the permite adotar um olhar crítico sobre sua condição de imigrante e sobre o país de acolhimento. Outro elemento que o diferencia é a incerteza da volta, ou melhor, a ausência do desejo de retomar sua existência no país de origem, silenciando com isso o surgimento do mito de retorno.

Diante desse cenário, esse personagem ficcional da primeira geração de imigrantes tem autoconfiança suficiente para exigir seu lugar como cidadão no novo espaço cultural e consegue imaginar sua existência a longo prazo naquele espaço de interação e negociação de sentidos. A partir desse cenário, este artigo deseja discutir a imagem do imigrante (1) no início de sua inserção no país de acolhimento, (2) no modo como administra as imagens do passado e, por fim, (3) na forma como reflete sobre a obtenção de uma voz própria no novo contexto nacional. 


\section{DEGRAU ZERO: O PROCESSO DE INSERÇÃO E REINVENÇÃO}

Uma das questões centrais que imigrantes da primeira geração precisam resolver é o modo como administrar o processo de inserção no novo espaço social e as adaptações necessárias para assegurar a chance de participação. Não havendo esforço nenhum em conhecer as regras do jogo na sociedade de acolhimento, a probabilidade de fracasso cresce substancialmente, já que a tendência de exclusão e negação de chances aumenta. Assim, o narrador rememora sua chegada:

Revejo-me na saída do aeroporto, espantando-me com o tamanho enorme dos automóveis, com a aparência moderna desta grande cidade, na qual eu podia enfim me perder, passar despercebido. Nada me ligava a ela, nenhuma lembrança, nenhum sofrimento. O estrangeiro usa uma máscara de aparência anódina para ser aceito, para que o deixem em paz. Não está seguro quanto aos outros, nem disposto a abandonar sua natureza profunda. Representa um papel para se integrar. Pelo orifício das órbitas, tenta ensinar a seu corpo essa dança, que arremeda, mas não sente. Como um negro num rinque de patinação, eu me agitava, desajeitado e desequilibrado, procurando não ser ridículo aos olhos deles. Só por um certo tempo, esperando que as coisas se ajeitassem no meu país (KOKIS, 2000, p.36). 
A primeira percepção foca na alteridade do espaço. A malha semiótica tecida nessas novas coordenadas de interação demanda do sujeito imigrante um esforço maior de decodificação, a fim de poder transitar com segurança nesse espaço. A transferência para o lugar desconhecido, contudo, não provoca o desconforto da voz narrativa, pelo contrário, ela enxerga nesse labirinto de sentidos uma chance de reconfiguração existencial. Esta, interessantemente, não está ligada a um desejo de reinserção célere nas malhas sociais, mas sim na oportunidade de recomeçar paulatinamente do nada. Concretamente isso significa a possibilidade de dar início a uma narrativa pessoal baseada naquele lugar de interação, sem o conhecimento prévio da estruturação do espaço e, sobretudo, sem qualquer elo emocional com outros atores sociais.

Essa ausência de relacionamento lhe permite um trânsito social e uma configuração do si que não precisam retomar narrativas anteriormente tecidas para evitar a ruptura causal ou a incoerência na concatenação de elementos identitários. Nesse sentido, o desejo de perder-se e não ser percebido remonta a um entendimento da identidade e suas imbricações sociais como algo negativo, uma vez que atualiza obrigações assumidas no que concerne ao modo como essa 
identidade é narrada. Desse modo, o recomeço contém um potencial massivo de liberdade não só na amplitude daquilo que pode ser inovado nas interações sociais e nas lógicas de representação simbólica, mas também na dimensão das memórias atreladas àquele espaço, que no início ainda são inexistentes.

Dada a ausência de memórias e experiências emocionais - a voz narrativa menciona sofrimentos - ainda não há uma esfera da identidade atrelada à constituição simbólica do corpo e seus potenciais de encenação social. As malhas das memórias afetivas interferem, muitas vezes inconscientemente para o sujeito, no modo como o corpo se coloca nas interações e o que este está disposto a processar nas diversas negociações inerentes às dinâmicas de encontros sociais. Sem essa carga afetiva, o protagonista tem todo um espaço emocional a desbravar, a fim de construir uma rede de memórias.

A ausência desses sedimentos da memória-espaçoemoção representa uma chance de liberdade para a reinvenção. Ao mesmo tempo, contudo, se revela como desafio, já que o protagonista estrangeiro precisa aprender a movimentar o corpo e administrar suas emoções em consonância com as práticas locais, com o objetivo 
primeiramente de alcançar aceitação e integração, o que, por sua vez, representa acesso ao recurso corporal de extrema importância que é a sensação de pertencimento. A metáfora da dança sintetiza esse esforço. Por um lado, os movimentos desconhecidos contêm um potencial de prazer, por outro lado, o prazer só pode ser alcançado por meio da decodificação competente das informações que os corpos alheios emitem e por meio da submissão de seu próprio corpo às novas regras de movimento. 0 medo do ridículo e da incapacidade de realmente incorporar os sentidos dessa dança revelam um sujeito marcado pela ambiguidade. $O$ novo espaço representa liberdade, mas também obrigação.

Ao contrário de muitos outros personagens oriundos do contexto de fluxos migratórios, esse protagonista, contudo, entende seu projeto de permanência no novo espaço cultural como provisório:

Não foi fácil no início. Principalmente porque cheguei pensando que isso seria provisório, para fazer um pé-de-meia e partir de volta. Era o que eu me dizia. Aqui, no estrangeiro. Nem vi passar os primeiros invernos; tudo era tão novo, tão confortável, tranquilo... Pouco a pouco, porém, desencadeou-se um processo insólito, discreto e extremamente eficaz: aceitar ser estrangeiro, exilado. Considerar provisórias todas as coisas, ser outro por trás das minhas aparências, perder-me nessas ruas limpas e quase desertas, entre gente desconhecida (KOKIS, 2000, p.35). 
Essa provisoriedade do projeto de permanência e, com isso, da internalização das práticas de interação e formação de sentido tende a diminuir a pressão de êxito no processo de adaptação. No lugar da exigência pessoal de inserção e reinvenção a partir das novas regras semióticas, permanece a possibilidade de romper a lealdade e a submissão a esse contexto cultural e retornar ao sistema de referências da primeira socialização. Essa estratégia de imaginação do futuro pode, até certo ponto, ser considerada como desejo da manutenção da liberdade experimentada na chegada ao novo país. Desse modo, a carga negativa do sistema referencial do país da primeira socialização, sentida como algo impositivo, não acaba sendo substituída pelo novo contexto cultural que, após o período de encantamento e deslumbramento, confronta o sujeito com suas práticas igualmente coercitivas de produção de sentido, acompanhadas de sedimentos de memória com experiências de prazer, mas também de dor.

Nesse sentido, o caráter provisório apresenta uma série de vantagens, pois garante ao protagonista a liberdade da indefinição. Com isso, o processo de reinvenção passa por um movimento de construção de um lugar próprio entre as duas culturas, não somente no sentido de mesclar práticas de formação de sentidos e, por meio da hibridização, construir 
redes semânticas próprias e autônomas. Trata-se também das dinâmicas de lealdade e pertencimento. Estas acabam se tornando mais complexas, criando redes múltiplas de afiliações, o que oferece ao sujeito uma paleta maior de acesso a recursos que podem oferecer prazer existencial em forma de aceitação, integração ou simplesmente atenção no marco do respeito. Por outro lado, permanece a indefinição não do sentido em si, que é instável por natureza, mas sim do projeto de futuro e da imaginação do lugar de fala do sujeito. Essa indefinição sistemática sugere a liberdade de escolha entres inúmeras possibilidades, criando um dispositivo que, em princípio, permite ao sujeito utilizar a máscara ou tecer a narrativa identitária com a qual mais se identifica num determinado momento existencial.

Somente num estágio muito mais avançado de sua permanência no exterior, vivendo na condição de imigrante, a voz narrativa analisa sua situação sob uma perspectiva completamente diferente:

Sirvo minha dose de vodca lembrando que há um quarto de século moro neste país. Não vi o tempo passar. Bebo para festejar ou para esquecer? Eis uma questão de que fujo. Nunca mais voltei a minha terra. Nem mesmo em férias. No começo isso não era mesmo possível, a situação estava tão instável que meus companheiros me aconselhavam 
a esperar mais um pouco. Como eu não tinha desejo de ir, toda desculpa era boa para adiar a volta (KOKIS, 2000, p.247)

O que no início pareceu como liberdade de reconfigurar a malha de sentidos e escolher entre diversas formas de concretizar a identidade longe das imposições da primeira socialização, vinte e cinco anos mais tarde apresenta uma coloração diferente. Com efeito, a voz narrativa se pergunta se sua motivação não esteve atrelada muito mais a um desejo de fuga. Esta talvez não motivada somente por razões políticas diante da instabilidade democrática que marcou a história do Brasil na segunda metade do século $X X$, mas possivelmente uma fuga do próprio si, com suas memórias dolorosas ou insuficientemente dominadas.

Diante desse cenário, a opção pela indefinição e a concentração na alteridade cultural do novo país podem representar mecanismos, com os quais o protagonista evita um confronto demasiado desconfortável com o passado e com uma identidade afetivo-corporal indesejada. Nessa virada de percepção, a inserção e a reinvenção do imigrante não são mais frutos de um processo completamente emancipado e autônomo. Na verdade, o protagonista se submete aos sedimentos da dor e age em consonância com as regras ditadas por essa configuração emocional. Com isso, a liberdade supostamente conquistada é uma fuga ininterrupta. 


\section{DOMESTICANDO AS IMAGENS DO PASSADO}

O enredo do romance, em grande parte, representa o trabalho de rememoração. Nesse esforço, o protagonista se concentra menos em sua experiência como imigrante, atribuindo muito mais atenção ao papel das experiências passadas no processo como ele se apropria do mundo e constrói sentidos no presente. Ao longo do desenvolvimento da trama, a voz narrativa vai obtendo um maior grau de clareza sobre o lugar das memórias em sua existência:

Dir-se-ia que, sem ter consciência disso, vim aqui para achar uma solidão propícia a minhas fantasias, para dar livre curso ao meu passado. [...]

Inicialmente eu ainda devia aprender o ofício, lutar com as imagens que se dissimulavam me perseguindo. Achava-me totalmente prisioneiro da realidade ambiente, buscava copiar as coisas em vez de fugir delas (KOKIS, 2000, p.36-37)

O acesso a esse conhecimento ocorre de modo intuitivo e lento, desenvolvendo um processo de simbolização e tomada de consciência ditado pelo princípio da dor, isto é, o protagonista vai se aproximando desses sedimentos do passado de acordo com aquilo que pode suportar conscientemente. Os excertos de experiências armazenados pela semiótica das emoções e do corpo que causam 
um desconforto excessivo permanecem obliterados, desconexos ou são causalmente concatenados de modo a reduzir o impacto ainda insuportável do confronto.

A busca pela solidão longe da família, de amigos e do país de origem pode estar atrelada ao desejo de encontrar um lugar onde os excessos de sentido produzidos no contexto de interação original deixem de imperar, desencadeando uma trégua que permita ao protagonista processar e ordenar as informações que foram relevantes em sua formação. Ao mesmo tempo, a voz narrativa expressa o desejo de explorar com mais atenção as memórias que flutuam em seu universo anímico e recuperar acontecimentos passados que foram armazenados de forma condensada como imagens para inseri-las numa rede de causas e efeitos. Há um anseio de compreender a semântica própria desses elementos que de algum modo foram simbolizados, mas cujos sentidos ainda esperam por uma decodificação ou atualização por parte do sujeito. Talvez seja possível compreender essas imagens como condensações emocionais, cujos traços permanecem na semântica do corpo, e que demandam do sujeito o trabalho de interpretação, ou seja, um esforço de torná-las conscientes, inserindo-as na rede de sentidos da narração de identidade. 
Esse trabalho de atribuição de sentido não é simples, já que a lógica inerente às imagens que formam a tessitura da memória não se submete ao desejo do protagonista. O princípio da dor, que permite ou não o surgimento consciente da imagem, ou o princípio da analogia ou associação livre que forma pontes semânticas entres conteúdos díspares dificilmente pode ser controlado pela volição do sujeito. Contudo, também nessa passagem parece haver uma ambiguidade, pois por um lado o protagonista procura a solidão, a fim de encontrar o ócio para dedicar sua energia à compreensão do passado. Por outro lado, as imagens assumem uma coloração negativa, quando a voz narrativa as caracteriza com lexemas oriundos de um campo semântico com conotações negativas como perseguição, dissimulação, prisão, fuga.

Entre desejo de compreensão e anseio de obliteração dessas imagens, o protagonista procura, antes de mais nada, dar conta do passado para compreender o presente. Nesses meandros reflexivos, ele tenta compreender o lugar dessas memórias em sua existência:

O poeta descrevia a lembrança como o despertar de uma criança durante a noite, enquanto os outros dormem profundamente. É uma imagem muito precisa. E se me pergunto hoje onde estão os outros, o pátio, o aterro, minhas putas e meus amores, sei que dormem profundamente. E estou só. 
Aqueles outros se enraizaram de maneira tão obstinada que em minha partida para o exílio eu trazia a tiracolo, sem o saber, os germes de uma impossibilidade absoluta de me fixar como estrangeiro. Os horizontes pareciamme abertos; tratava-se simplesmente de partir de lá. Ignorava então que veria todas as novas paisagens através do caleidoscópio do Mangue, do carnaval e das paredes ressumando umidade, verde-cinza e salobras do pátio imundo. Sem intenção de voltar, tornei-me então um homem de lugar nenhum. (KOKIS, 2000, p.157-158)

Até certo ponto, ele parece sugerir um determinismo, não biológico darwinista, mas sim da memória. Isto é, os sedimentos da memória em forma de resquícios, gravados na carne, de experiências afetivas majoritariamente dolorosas imperam sobre o sujeito, determinando sua visão de mundo, sua apropriação de realidade e, por consequência também, a narração de identidade. Toda a máquina de produção cotidiana de sentidos passa inconscientemente por esse crivo, destilando novos sentidos que em sua origem estão impregnados pelos sedimentos que se assentaram na imagem do si, ao longo da existência. Talvez seja possível dizer que da mesma forma que a base genética condiciona a produção do material biológico, as memórias funcionam como matriz dos sentidos que o sujeito consegue instaurar. 
A consequência lógica disso para a condição de imigrante é que esta está condicionada também pelas memórias que o imigrante traz consigo. Diante desse cenário, as inúmeras discussões sobre multi, inter ou transculturalismo possivelmente perdem um pouco de sua relevância, já que o imigrante não é fruto somente de um sistema de referências culturais e do processo de socialização num determinado espaço de interação. Isto é, a compreensão das alusões ao mangue, ao carnaval ou ao sistema político do país de origem certamente fornecem uma imagem mais nítida do modo como esse imigrante, em específico, produz sentidos. Ao mesmo tempo, contudo, não é a referência cultural em si que é suficiente para compreender esse fenômeno, mas sim o modo como o sujeito interage com esses elementos e o impacto que eles têm na sua economia afetiva, produzindo uma apreensão específica da realidade e, por conseguinte, uma tessitura da memória que irá funcionar como base da produção de sentidos.

Com base nisso, o protagonista começa a rever a processamento das imagens que o afetaram, buscando domesticá-las, a fim de reaver o controle sobre os sentidos que vão surgindo em seu horizonte. É questionável até que ponto essas memórias permitem ser disciplinadas. $\mathrm{O}$ protagonista tem ciência dessa limitação, da precariedade 
da autonomia e da necessidade de investimento constante de energia, para ao menos alcançar uma compreensão mais aprofundada da memória como crivo existencial.

\section{VOZ E LÍNGUA PRÓPRIAS}

A apropriação dos mecanismos de fala e de participação discursiva provavelmente estão entre os maiores desafios a serem resolvidos na condição de imigrante. O estabelecimento de uma voz própria implica uma aproximação às práticas culturais do país de destino, com suas idiossincrasias hierárquicas, mas também significa não renunciar à bagagem discursiva que o imigrante traz do país de origem, pelo menos no caso da primeira geração. A voz própria, portanto, surge desse embate de diferentes modos de interpretar a realidade e representá-la, pré-organizando as interações cotidianas. Num primeiro momento, esse embate parece ser definido somente a partir das estratégias culturais:

Em Paris, encontrei alguns companheiros chegados antes de mim, e já bem adiantados na arte de passar despercebido na Europa. Uma arte complexa à qual sulamericanos e africanos se dedicam com disposição. Conheci um português que vivia em Estrasburgo desde a adolescência e desempenhava como ninguém o papel de francês. Estava sempre sério e vigiava sem descanso a si próprio, como se estivesse 
num palco. Quando ficávamos sozinhos, ele se distendia, sorrindo, feliz por falar sua língua e de trocar lembranças longe de olhares indiscretos. Depois se enquadrava de novo como seu dublê, e não se saberia dizer qual dos dois era o verdadeiro. (KOKIS, 2000, p.162-163)

Assim, quando o protagonista narra suas experiências durante sua estada na França, ele relata a percepção que ele tem da experiência de seus conhecidos, na técnica de ser estrangeiro. O que caracteriza esse modo de interação é o desejo de apagar as marcas da diferença, a fim de acelerar o processo de pertencimento. O afinco com o qual seus companheiros se dedicam à obliteração da diferença indica a importância atribuída ao desejo de pertencer. Este representa um recurso central, já que não garante somente o acesso ao capital econômico por meio de chances de trabalho, crescimento no mercado ou mesmo permanência nesse espaço de interação, ele também inclui o acesso a recursos afetivos de atenção, gentileza e generosidade. Tanto os recursos econômicos como socioafetivos vão criar uma base de sentido existencial que vão fornecer a estabilidade necessária para a continuação do processo de negociação das vozes que definem a produção de sentido.

Esse desejo de pertencimento também tem um impacto sobre outra esfera, que não a cultural, a saber, o modo de semantizar o corpo e seus afetos. Não raramente a discussão 
em torno da condição do estrangeiro se limita à questão da diferença cultural, e ela obviamente é importante para compreender os processos de inclusão e exclusão de atores sociais que optam ou são forçados a fluxos migratórios. Contudo, outras esferas também definem a figuração do estrangeiro que são insuficientemente discutidos, se limitados ao princípio do determinismo cultural. Dentre essas esferas, se encontra a administração da memória formada a partir da experiência subjetiva, como discutido na seção anterior, mas também o corpo como superfície de sentidos.

Desse modo, surge - ou não - um corpo domesticado apto a participar da sociedade, nos moldes daquilo que Norbert Elias (1976) discutia para um contexto completamente diferente, no processo de civilização. Contudo, também aqui o corpo desempenha um papel fundamental na lógica de poder, isto é, sua domesticação permitirá que o sujeito participe dos atos de fala. Quando a voz narrativa utiliza a metáfora da atuação teatral para representar o desejo de apagamento da diferença, ele atualiza todo um campo imagético que começa pela instrumentalização do corpo e também da voz para surtir efeitos. A superfície do corpo e todos seus mecanismos são utilizados, nesse contexto, para o afrancesamento. A imagem da atuação, contudo, também indica que se trata de um papel desempenhado pelo ator social, a fim de fazer crer 
que faz parte desse universo narrativo, o qual poderia ser transferido para o contexto mais amplo do palco da nação. A voz que surge dessa atuação é fruto do desejo de convencer um público de um determinado conjunto de sentidos.

Fora dos palcos, o corpo e a voz revelam um desempenho completamente diferente, o que não significa que menos legitima. A voz narrativa chega a indicar a dificuldade de identificar quais das duas atuações está mais próxima daquilo que o sujeito em questão realmente é. Contudo, há uma diferença essencial e esta reside na dinâmica afetiva. Enquanto a primeira exige um empenho de energia, a fim de alcançar os resultados desejados, a segunda não demanda o mesmo foco, pelo contrário, o sujeito se permite não controlar e domesticar corpo e afetos, deixando que essa superfície semiótica siga sua lógica própria de constituição de sentidos. Esse fluxo desimpedido também produz uma coloração afetiva muito mais positiva, no sentido da afirmação existencial. A voz que surge nessa configuração de pertencimento é completamente diferente daquela articulada no ato do desempenho de um papel socialmente exigido ou desejoso de obliteração da diferença.

Em ambos os casos, a voz é mais que um produto da cultura, ela surge a partir da lógica própria do corpo com sua administração afetiva. Nesse sentido, a voz narrativa escreve: 
"Esforçava-me por seguir o jogo teatral dos outros, mas ficava cada vez mais claro que havia uma roupa do estrangeiro colada à minha pele. Minhas bagagens, na verdade, não eram tão poucas como eu tinha desejado na partida" (KOKIS, 2000, p.163). A bagagem mencionada se refere certamente à cultura, mas também inclui os sedimentos da memória e o panorama afetivo que constituem o amálgama dessa voz. Nesse sentido, o desejo de obliteração da diferença está a serviço do desejo de pertencimento, mas à custa da renúncia de uma parte importante do próprio patrimônio de sentidos.

A voz narrativa assume uma posição ambígua nessa discussão. Por um lado, sua percepção do comportamento de seus companheiros estrangeiros indica um posicionamento crítico que questiona o princípio do apagamento das marcas, com sua submissão à cultura hegemônica. Por outro lado, contudo, esse comportamento também parece imperar na forma como o narrador interage com outros atores sociais:

Se fico à vontade, as frases saem lógicas, mas num dialeto bastardo, que pode ser tudo mas não tem fisionomia própria. Algumas formas de expressão ou o uso da gíria num contexto inadequado às vezes podem chocar meus interlocutores, que entretanto não reagem, por causa de minhas boas intenções. Há casos em que pretendo realçar uma expressão e o faço de maneira inusitada, o que destrói o efeito desejado. Bem sei de todas essas coisas, que de resto percebo em 
outros estrangeiros, mas minha tendência é esquecê-las quando se trata de mim. Não se pode estar preocupado com isso a cada momento, senão o raciocínio se interrompe, a cabeça de vaga e perde-se o fio da meada. (KOKIS, 2000, p.227)

Como no relato sobre a percepção do amigo, também o estado do corpo da voz narrativa tem um impacto no desempenho da sua representação. A língua falada apresenta a coloração específica do estrangeiro. No entanto, apesar do grau de reflexividade do narrador e de sua capacidade de distanciamento crítico, ele também internaliza o desejo de obliteração. Quando sua própria percepção não lhe permite ignorar sua diferença, adota a estratégia da repressão, preferindo esquecer a reconhecer a diferença. Isso funciona como estratégia de administração do equilíbrio afetivo, mas em detrimento da afirmação autônoma da voz.

Nesse sentido, ao contrário de outros personagens imigrantes que tem um posicionamento claramente subversivo, de militância contra imposições do grupo hegemônico (MATHIAS, 2016a; MATHIAS, 2018) e muito próximo do conceito de carnavalização de Bakhtin (1987), este protagonista revela um embate muito mais ambíguo, não abandonando um comportamento subversivo, mas tampouco atribuindo importância central à negociação cultural. Com efeito, em grande parte, da narrativa o foco 
não recai nas interações com representantes da outra cultura, mas sim no modo como a voz narrativa administra suas memórias, seu equilíbrio afetivo e impacto que isso tem na condição de estrangeiro, como Zsuzsa Bánk (MATHIAS, 2016b) o faz no contexto da literatura de imigração alemã. A voz que resulta desse embate tem sua origem num espectro mais amplo e complexo de questionamentos e negociações.

\section{CONSIDERAÇÕES FINAIS}

O caminho traçado por esse protagonista imigrante é peculiar, longe de concepções essencialistas de cultura. No lugar de imaginar a condição do imigrante unicamente definida a partir de culturas diferentes que se encontram ou, muitas vezes, se chocam, a voz narrativa empreende um caminho de reflexão que se concentra em outros aspectos da experiência imigrante. Assim, o início no novo espaço cultural também está marcado pela necessidade de apropriação do conhecimento cultural para garantir interações satisfatórias, ao mesmo tempo, contudo, o protagonista igualmente enxerga um potencial de ressignificação de sua narrativa identitária a partir da ausência de laços e sedimentos afetivos. Esse início no degrau zero da balança afetiva, no entanto, acaba sendo relativizado ao longo do desenvolvimento reflexivo empreendido pelo narrador, considerando-a vantajosa dada a liberdade que ela concede, mas também 
indicando que no cerne se trata de uma fuga, motivada pelo desejo de esquivar um confronto doloroso com o passado.

Diante desse conhecimento, grande parte do esforço reflexivo da voz narrativa é canalizado em direção ao disciplinamento da memória. Sua organização e concatenação causal busca reaver um controle por parte do protagonista, a fim de evitar que as memórias determinem suas ações. De fato, são as memórias que vão servir como matriz na produção de sentidos. A partir dessa base de formação de sentidos, também surge a voz própria dessa voz narrativa. Por um lado, ela está marcada pelas memórias, por outro, ela é definida pelas lógicas da encenação do corpo. Nisso, o protagonista revela um comportamento ambíguo de aproximação e distanciamento da cultura hegemônica local. Nesse sentido, A casa dos espelhos é um romance que busca identificar outras dimensões da condição do imigrante, criando uma imagem complexa, distante de configurações dicotômicas.

\section{REFERÊNCIAS}

BAKHTIN, Mikhail (1987). A cultura popular na Idade Média e no Renascimento: o contexto de François Rabelais. Yara Frateschi Vieira (Trad.). São Paulo: Hucitec.

BOURDIEU, Pierre (1983). Ökonomisches Kapital, kulturelles Kapital, soziales Kapital. In: KRECKEL, Reinhard (Ed.). Soziale Ungleichheiten. Göttingen: Otto Schwartz, p.183-198. 
ELIAS, Norbert (1976). Über den Prozeß der Zivilisation. Erster Band: Wandlungen des Verhaltens in den weltlichen Oberschichten des Abendlandes. Frankfurt am Main: Suhrkamp.

KEUPP, Heiner et alia (2002). Identitätskonstruktionen. Das Patchwork der Identitäten in der Spätmoderne. Reinbek bei Hamburg: Rowohlt.

KOKIS, Sergio (2000). A casa dos espelhos. Marcos de Castro (Trad.). Rio de Janeiro/São Paulo.

MATHIAS, Dionei (2016). "Seriedade e subversão em Kanaken-Gandhi, de Osman Engin". MOARA, 46, 249-266.

MATHIAS, D. (2016). "Herança da imigração: luta por coerência em Der Schwimmer, de Zsuzsa Bánk". Antares: Letras e Humanidades, 8, 316-329. MATHIAS, Dionei (2018). “Wie zwei perfekt integrierte Vorzeigeausländer: Figurações do estrangeiro, em Olga Grjasnowa". Miguilim - revista eletrônica do net/li, 7, 256-266.

Dionei Mathias é Doutor em Letras pela Universidade de Hamburgo e pela Universidade Federal do Paraná. Professor da UFSM, no Departamento de Letras Estrangeiras Modernas e no Programa de Pós-graduação em Letras. E-mail: dioneimathias@gmail.com 